\title{
Skeletal Muscle Disorders of Glycogenolysis and Glycolysis
}

\author{
Richard Godfrey $^{1,2}$, Ros Quinlivan ${ }^{2,3}$
}

\author{
${ }^{1}$ Division of Sport, Health and Exercise Science, Brunel University, London, UK \\ ${ }^{2}$ MRC Centre for Neuromuscular Diseases, Institute of Neurology, London, UK \\ ${ }^{3}$ Dubowitz Neuromuscular Centre, Great Ormond Street Hospital, London, UK
}

\section{*Address for correspondence}

\begin{abstract}
This review will focus specifically on the disorders of glycogenolysis and glycolysis (glyco(geno)lytic) affecting skeletal muscle. McArdle disease (GSD V) is the most common with an estimated incidence: 1:100,000-167,000 and is caused by mutations in the gene encoding muscle glycogen phosphorylase. Symptoms include exercise intolerance, muscle contracture, muscle atrophy and weakness, acute rhabdomyolysis and risk of acute renal failure. Acute rhabdomyolysis (AR) is precipitated by strenuous activity and isometric muscle contraction, but can be prevented with appropriate advice. Individuals with GSDV experience a 'second wind' phenomenon during exercise which is characterised by abatement of symptoms and improved exercise tolerance after about 8-10 minutes of aerobic activity.

Apart from branching enzyme and PGM1 deficiencies, the other muscle specific glyco(geno)lytic disorders present with similar symptoms to GSDV of varying severity. Diagnosis is frequently delayed due to their rarity and lack of access to appropriate investigations. Some may have additional features such as mild haemolysis, liver disease and neurological features.
\end{abstract}


For all of these conditions, it seems likely that engaging with exercise will be beneficial resulting in improved physical capacity, reduced risk of contracture, rhabdomyolysis and acute renal failure; improved functionality and improved quality of life. There have been few randomised clinical trials, some studies have focussed on dietary modification although the quality of the evidence is low and no specific recommendation can yet be made. The development of an international registry for these disorders (EUROMAC) should improve our knowledge of their natural histories and provide a platform for future clinical trials.

\section{Key points}

- Of the glycol(geno)lytic disorders McArdle disease (GSD V) is the most common with an estimated incidence of 1 in 100 000-167,000 and beta-enolase deficiency the rarest where, currently, only 3 patients have been identified.

- All the disorders are the result of autosomal or X linked recessive mutations resulting in a specific enzyme deficiency leading to the inability to utilize muscle glycogen as an energy substrate.

- The main features include exercise intolerance and myoglobinuria. Most experience pain associated within minutes of physical activity. Risks associated with later development of secondary health threats from a sedentary lifestyle are common for all as is a reduced quality of life.

- Additional clinical features such as dysmorphic features, haemolysis, neurological features, liver disease, skin lesions and or cardiomyopathy can help to pinpoint the specific enzyme deficiency.

- In many cases improperly regulated physical activity can cause severe problems with increased risk of morbidity and mortality. Paradoxically, when appropriately 
prescribed, exercise can improve work capacity, reduce health risks, ameliorate symptoms and improve quality of life.

- Research remains quite limited but treatment potential is being explored, particularly in McArdle disease, with the use of animal models of the disease (cattle, sheep and mice) and in humans through dietary manipulation and speculative drug therapy. In addition, a European database (EUROMAC) has been established to pool and transfer knowledge more effectively.

\section{Introduction}

Physical activity is inherent to the human condition and hence to normal daily existence for every individual on the planet. Even the most economical physical activity requires that skeletal muscle have adequate supplies of substrate to fuel energy demand. As a result, evolution has fostered the development of sophisticated energy management via metabolic processes whether for the most basic tasks of everyday living, such as personal hygiene and paid work; to achieving the pinnacle of human sporting prowess, a gold medal at an Olympic Games.

Amongst Eukaryotes sexual reproduction is the major form of preserving species genomes and with it is the opportunity for myriad genetic mutations which have, over thousands of millennia, formed the basis of speciation and individual variation. A huge number of genetic mutations are random and arise by chance and so the outcomes lie on a continuum, with great advantage at one end of the spectrum (an improved 'fit' of individual to environment) and an incompatibility with life at the other.

Mutations of genes associated with disruption or deletion of enzymes of carbohydrate metabolism are numerous, with some being more common than others. Most are referred to as glycogen storage diseases (GSDs) with a combined incidence of between 1 in 20000 to 1 
in $43000^{1}$. For the purposes of this review, however, only muscle disorders caused by enzyme deficiencies associated with glyco(geno)lysis will be considered, Table 1 provides a summary of the disorders covered by this review. We will not discuss Pompe disease (GSD type II) as this has already been the subject of a previous review on lysosomal pathology in Nature Reviews ${ }^{2}$.

Since carbohydrate is a major substrate in mammalian metabolism (the others being, in order of significance: lipids and amino acids), reduced access to stored carbohydrate results in pathologically restricted physical activity. In the context of this work, physical activity is considered an umbrella term, embracing all forms of activity from 'non-exercise activity thermogenesis' (NEAT) ${ }^{3}$, that activity which is incidental to everyday living, to 'exercise', which, in contrast, is the deliberate, planned implementation of physical activity which has a defined purpose (e.g. to improve level of conditioning, and or to improve health status).

The enzymatic pathways involved in glyco(geno)lysis are shown in figure 1, not only do deficiencies of these enzymes have implications for the capacity to carry out muscular work but often there are additional signs and symptoms which are specific to each condition which can affect function, health and future disease risks more generally. Another important consideration which can aid identification of these patients in the clinic is that the enzyme deficiency affects all skeletal muscles, thus symptoms are not confined to the legs but also face, neck, arms, trunk. For each specific condition there are general features which, once a sufficient physiological and pathological profile has been compiled, can aid diagnosis and subsequent management. Further complications can also exist however, as phenotypic variation is found and modified by epigenetic stimuli which affect expression often as a result of individual lifestyle choices but also by exposure to many environmental factors. 
Even for the most common of these disorders, McArdle disease (GSDV), knowledge and understanding is not widespread across the medical community and hence diagnosis has traditionally been slow with the majority of affected individuals only receiving the correct diagnosis on average 20 years after their first presentation to a clinician ${ }^{4}$. In childhood, symptoms, because of their paroxysmal nature, are commonly dismissed as 'laziness' by teachers and health professionals with the consequence that many are compelled to physical activities to the point of muscle damage and so are exposed to rhabdomyolysis, but also the difficulties of achieving these activities can result in psychological issues particularly low self-esteem and stigma ${ }^{4}$. Paradoxically, aerobic exercise can and should be prescribed in all cases of GSD as appropriate exercise prescription can improve functionality, reduce health risks and improve quality of life. However, knowledge and great care is required in prescribing exercise as mistakes can have serious and far-reaching consequences ${ }^{5}$.

Nomenclature of GSDs generally follows two principles; named after the individual who first identified the disease and a GSD number based on the chronological order of their description. In some cases, particularly relating to exceptionally rare GSDs, the deficient enzyme is used.

\section{McArdle disease / GSD V}

This condition was first described by Brian McArdle in 1951 in a patient who failed to produce lactate during ischaemic exercise ${ }^{6}$ and is the result of autosomal recessive mutations in PYGM, the gene encoding for muscle glycogen phosphorylase ${ }^{7}$. In the UK, Northern Europe and USA the majority of affected individuals have homozygous or compound heterozygous nonsense mutations at R50X (originally described as R49X), although at least 147 pathogenic mutations and 39 polymorphisms have been described so $\operatorname{far}^{8}$. The incidence is believed to be in the region of 1:100 000-1:167,000, although accurate epidemiological data are lacking ${ }^{9,10}$. In affected people there is absence of enzyme muscle 
glycogen phosphorylase, which normally catalyses the conversion of muscle glycogen to glucose-6-phosphate in the Embden-Myerhof-Parnas (glycolytic) pathway (figure 1). Interestingly, patients with a rare splice site mutation resulting in a small amount of residual enzyme (1-2.5\%) have been described with a milder phenotype evident with exercise testing $^{11}$ This suggests that only very low levels of PGM are sufficient to ameliorate symptoms- an important observation for possible therapeutic strategies in the future.

Since typically, 503g of carbohydrate is available for use in those without pathology: $400 \mathrm{~g}$ muscle glycogen, $100 \mathrm{~g}$ liver glycogen and $3 \mathrm{~g}$ of glucose circulating in the blood stream, people with McArdle disease have access to just $20 \%$ of that carbohydrate in comparison with healthy individuals ${ }^{12}$ (Figure 2). As a consequence there is abnormal storage of muscle glycogen in sub-sarcolemmal vacuoles seen on muscle histology. Histochemistry shows absence of the enzyme muscle glycogen phosphorylase apart from residual staining in smooth muscle on blood vessels of the brain/foetal isoform (Figure 3).

At the start of aerobic exercise, such as walking, muscle contraction is fuelled by ATP already attached within the muscle fibre. ATP is hydrolysed to ADP, the breaking of a phosphate bond providing the free energy $\left(\Delta \mathrm{G}^{\mathrm{o}}\right)$ for the 'power stroke', with actual movement seen in the shortening of the sarcomere ('sliding filament theory', the accepted mechanism of muscle contraction $\left.{ }^{13,14}\right)$. ADP is reconstituted from intramuscular stores of creatine phosphate by donation of Pi. However, this process is soon outstripped by demand and since, in people with McArdle disease, other sources are not yet available leading to an energy crisis causing the heart rate to increase sharply together with symptoms of discomfort and fatigue in the exercising muscle. This requires the individual to slow down or to stop the activity, allowing symptoms to subside or disappear before exercise can continue. Upon recommencing activity, symptoms may again appear but should soon diminish, alongside a decrease in heart rate (at between 8-10 minutes into continuous physical activity), as a result 
of the increased supply of ATP associated with increased efficiency of fat oxidation and improved muscle blood supply. The lag is created by the time taken to increase the rate of fat oxidation to an appropriate level to meet a relatively modest demand, with respect to intensity of effort. The abrupt easing of symptoms and attendant, sudden increase in exercise capacity, is known as the 'second wind' phenomenon ${ }^{15}$ and is a specific characteristic of this condition and so is considered pathognomonic for McArdle disease ${ }^{16}$. In McArdle disease, blood lactate, which is an obligate feature of normal physiology associated with increasing exercise intensity, fails to rise compared with normal healthy individuals. Lactate itself represents a highly significant fuel source during exercise ${ }^{17,18}$ (Figure 4) which is, of course, lacking in this patient population.

Without careful management during the early stages of physical activity to ensure that the second wind is achieved, there is a significant risk of contracture and rhabdomyolysis. Muscle contracture is a type of muscle cramp which is electrically silent ${ }^{19}$ and is common in McArdle disease leading to muscle damage and rhabdomyolysis ${ }^{4}$. As a consequence, when performing exercise assessments in this patient population, on either an exercise bike ${ }^{20}$, treadmill or corridor using a 12 minute walk test $(12 \mathrm{MWT})^{21}$ heart rate is generally monitored alongside the use of the CR10 pain rating scale (RPP) or Borg rating of perceived exertion $(\mathrm{RPE})^{22}$.

The 12MWT is a useful measure that can be done in a clinic setting without the need for specialist equipment. Immediately prior to commencing the test, the RPP scale is explained to the patient, to anchor the ends of the range descriptors. During exercise testing, efforts are made to ensure that pain does not exceed a rating of '4', as levels above this are much more consistent with the onset of muscle contracture. Testing of this type should occur on a regular basis for clinical monitoring, with the total distance walked being recorded as an outcome measure of current level of function and to monitor improved function between 
successive test periods. By monitoring the heart rate each minute during the test, the second wind is often evident ${ }^{21}$. A functional cycle test can also be very useful for monitoring patients, but requires specialist equipment and trained staff, however, it provides a highly useful and validated outcome measure for research studies ${ }^{20}$.

Optimum clinical management includes exercise prescription designed to increase both function and capacity for physical activity whilst minimising acute risk of contracture. The long-term objective being increased ease of daily function with lower health risk and subsequent improved quality of life. This can be achieved by instructing patients on how to reach a second wind for each muscle group that is to be used subsequently, and the setting of short terms goals. The first major aim being to comply with the minimum recommended guidelines for exercise for health of 150 minutes per week, distributed as five days per week at moderate intensity ${ }^{23,24}$. The benefits of regular exercise are well known and higher levels of physical conditioning ('fitness') are highly correlated with reduced health risks ${ }^{25,26}$ and improving physical conditioning by even very modest amounts $(1 \mathrm{ml} / \mathrm{kg} / \mathrm{min}$ improvement in VO2max ${ }^{27,28}$ or 1 MET improvement in exercise capacity ${ }^{29}$ ) can result in a $10-12 \%$ reduction in health risks and all-cause mortality.

\section{Exercise and McArdle Disease}

Where there is little doubt that physical activity and exercise is beneficial, the perceived risk of moderate to high intensity exercise amongst these patients is high and the suggestion that it may be possible to exercise at higher intensities and to include resistance exercise (weight training) is contentious because of the high risk of acute rhabdomyolysis, however, resistance training albeit with close supervision, has been successfully achieved in people with McArdle disease ${ }^{30}$.

In a number of other pathologies (e.g. heart disease, type II diabetes) higher intensity exercise (particularly aerobic high intensity interval exercise) is increasingly demonstrated to 
be efficacious for amelioration of symptoms and in improving function ${ }^{31-36}$. For many years testing the VO2peak (maximal oxygen uptake) of people with McArdle disease was generally considered impossible for fear that the required high intensity of effort would increase the incidence of adverse events such as contracture, rhabdomyolysis, renal failure and attendant increased mortality risk. However, in Spain testing of VO2peak in people with McArdle disease has occurred since 2006 and is challenging this perception. Data collected on 81 participants all with a diagnosis of McArdle disease have found positive significant correlations when comparing cardiorespiratory fitness (VO2peak) with quality of life and an inverse relationship with severity of impairment ${ }^{37}$. This suggests that people with McArdle disease benefit generally by being sufficiently active to improve cardiorespiratory conditioning and some may adapt to be able to tolerate higher intensity efforts and so further reduce risks associated with their pathology.

A study of eight participants with McArdle disease training at $60-70 \%$ of peak heart rate during cycling sessions lasting 30-40 minutes for 14 weeks demonstrated a $36 \%$ improvement in peak work capacity, as well as improvements in peak cardiac output, and indicators of improved muscle oxidative capacity, increased citrate synthase and betahydroxyacetyl CoA dehydrogenase ${ }^{38}$.

The consensus on resistance training (using weights) is generally a negative one for this population but research evidence contradicts this perception. Santalla et al ${ }^{39}$ recently conducted (2014) a four month resistance training programme using 7 adults confirmed to have McArdle disease by genetic testing. Participants trained twice a week at the same venue and were always supervised and had undergone two sessions of instruction to ensure they could safely undertake weight lifting. Power velocity curves were constructed for each patient for half squat (lower body assessment) and bench press (upper body assessment) before and after the 4-month training intervention. A significant improvement in lean mass 
was noted $(\mathrm{P}<0.05)$ and significant improvements in muscle strength for both upper and lower extremities (bench press improved by $52 \mathrm{~W}, 95 \% \mathrm{CI}: 13,91$ and half squat improved by 173W, 95\% CI: 96, 251) was demonstrated without any serious adverse events. As a consequence in this study, all patients saw a change to a lower severity class for their disease. Clinical improvements persisted even after a detraining period with all participants being classed as mild for disease severity. This suggests that addition of resistance training could be an extremely useful adjunct to aerobic exercise, since one of the consequences of having McArdle disease is that increasing muscle mass is difficult. As a consequence with advancing age there is muscle atrophy and weakness especially involving shoulder girdle and paraspinal muscles, in addition, semi-acute muscle atrophy following injury may be permanent. The proviso however, is the use of appropriately qualified and experienced staff being available to closely supervise every training session. This approach, however, would have significant financial and staff resource implications.

\section{Basic and applied research}

A number of approaches have been undertaken with respect to potential treatment of McArdle disease including dietary manipulation and invasive research intervention using animal models for the disease ${ }^{40,41}$.

\section{Diet}

Creatine supplementation has been used to enhance purine nucleotide cycling but, although it did increase CK activity in patients, in high dose, it caused increased pain and inhibited tasks of everyday living ${ }^{40}$ and subsequent consensus was of no clinical benefit ${ }^{41}$.

Ingestion of sucrose ( $75 \mathrm{~g}$ in $660 \mathrm{ml}$ solution, 40min before exercise) increased blood glucose by more than $2 \mathrm{mmol} \cdot \mathrm{L}^{-1}$ and resulted in a large reduction in $\mathrm{RPE}$ and a reduction in heart rate of $34 \mathrm{bt} \cdot \mathrm{min}^{-1}$ during exercise on a cycle ergometer ${ }^{42}$. Further studies confirmed 
that sucrose or fructose can improve exercise tolerance and capacity, increases well-being and may reduce the risk of exertional rhabdomyolysis ${ }^{42,43,44}$.

Since people with McArdle disease cannot access the majority of their endogenous carbohydrate stores and because they have 'exaggerated' lipid oxidation ${ }^{45}$ there has been speculation as to the potential benefits of a ketogenic diet ${ }^{46}$. Indeed, there are anecdotal reports from individual patients who have tried it themselves who report improved exercise capacity and reduced incidence and magnitude of symptoms. Further studies including randomised controlled trials are now required to objectively test these subjective findings.

\section{Animal models}

A number of animal models are available for further research on the potential to treat McArdle disease including bovine, ovine and murine models ${ }^{47}$. A study using notexin, a myotoxin derived from the venom of the Australian tiger snake (Notechis scutatus) was injected into the muscle of live sheep. Muscle biopsies were taken pre and 21 days post injection and compared with untreated sheep muscle. Notexin initially caused muscle necrosis followed by regeneration with some fibres expressing both non-muscle isoforms of phosphorylase (brain/fetal and liver) with resultant increased force of muscle contraction and reduced fatigue. The authors concluded that future research should further examine the potential of re-expression of these isoforms as a treatment for McArdle disease ${ }^{48}$. More recently, sheep were given sodium valproate, administered systemically by enteric route, this drug normally used for the treatment of epilepsy has HDAC qualities which might potentially affect chromatin and gene expression. Although mobility was unaffected re-expression of phosphorylase did occur in a dose-dependent manner reaching a peak in 2 hours and so suggests another possible avenue of investigation for treatment of human McArdle disease ${ }^{49}$. 


\section{Cori Disease / Forbes Disease / GSD type III}

This disorder is the result of autosomal recessive mutations of the $A G L$ gene, which result in deletion of the enzyme, amylo-1,6- $\alpha$-glucosidase, 4 - $\alpha$-glucotransferase (more commonly referred to as 'debranching enzyme') with an incidence of less than 1 in 100000 . There are four subtypes (types IIIa, IIIb, IIIc and IIId) and their existence and the consequent variation in symptoms is explained by tissue differences in enzyme expression. The majority of affected people lack the enzyme in both muscle and liver (type IIIa) with only around 15\% lacking it in liver only (type IIIb) ${ }^{50}$. Deficient enzyme in cardiac muscle leads to late onset cardiomyopathy $^{51,52,53}$.

The usual presentation is in infancy or early childhood with hepatomegaly, hypoglycaemia, and growth retardation which improves with age. However, in type IIIa progressive skeletal muscle atrophy and weakness together with cardiomyopathy develops in adulthood. Serum CK is raised and muscle biopsy shows abnormal glycogen storage ${ }^{50}$. Although diagnosis can be confirmed without muscle biopsy by measuring enzyme levels in red blood cells and confirmatory DNA studies ${ }^{54}$. Exercise intolerance is a function of both muscle weakness (mainly arising from atrophy and fatigue) and energy deficiency. The energy deficiency arises from the inability to debranch glycogen ${ }^{55}$, which is partially compensated for by increased lipid oxidation as elucidated by isotopic labelling ${ }^{56}$ but also from altered peripheral blood flow which contributes to a slowing of recovery ${ }^{57}$.

\section{Tarui Disease / GSD type VII}

Named after the Japanese physician Seiichiro Tauri who first identified phosphofructokinase (PFK) deficiency in $1965^{58}$, this disorder is generally the result of mutations in the PFK-M gene, although since PFK comprises three distinct subunits each encoded by a different gene, mutations associated with PFK-L (liver) and PFK-P (platelet) genes are also possible ${ }^{59,60}$. In common with other glycolytic disorders symptoms are of pain, 
exercise intolerance, muscle contracture and rhabdomyolysis. Although exercise intolerance tends to be more severe than in McArdle disease and there is no second wind reported. Indeed patients describe an 'out of wind' phenomenon whereby the administration of glucose prior to exercise worsens exercise capacity by 'blocking' fatty acid oxidation. One interesting reported phenomenon is the development of nausea and vomiting with exertion, this is not described in any of the other related glycolytic disorders. In addition, the glycolytic pathway in red blood cells is affected as a consequence of disrupted $\mathrm{Ca}^{2+}$ homeostasis and so a specific feature of the condition is mild compensated haemolysis ${ }^{61}$. As in McArdle disease, hyperuricaemia and gout are also common features. Fixed muscle weakness is common with advancing age and a specific phenotype mimicking limb girdle muscular dystrophy has been reported. A fatal infantile form associated with arthrogryposis and brain malformation has been reported, but appears to be a distinct genetic entity ${ }^{62}$.

Tarui disease is a very rare condition with only around 100 patients so far reported in the literature it is more prevalent amongst those of Ashkenazi Jewish origin and or those of consanguineous heritage $\mathrm{e}^{63}$. The disease is more common in $\log _{\mathrm{s}}{ }^{64}$ which may therefore represent a good animal model for future study.

Prescription of exercise in this population is also likely to be beneficial although there have been no clinical trials. In this population, more frequent pauses are likely to be required and the 'second wind' phenomenon, so characteristic of McArdle disease, is absent. Exercise prescription must be much more tailored to this condition and thus, from our own experience, the best advice may be 'little and often'. In practice, this may mean utilising stored ATP during very short bouts of exercise with intervals of only six seconds at a time before implementing a short a rest of 10-20s, this strategy, used in our clinical practice is based upon established doctrine in sports and exercise physiology whereby 6-10 seconds worth of stored ATP could be utilised for bursts of energy. Whether or not this exercise format imposes 
sufficient appropriate stimuli (of both intensity and or duration) to encourage beneficial adaptation, in terms of both function and reduced risk of secondary diseases of hypokinesis (such as type II diabetes and heart disease), is unknown. This could, however, be an area of further research to determine acute responses and identify any chronic adaptation which may improve function and quality of life.

\section{Glycogen phosphorylase b kinase deficiency / GSD type IX}

This disorder is often described as being 'at least four different conditions' (GSD types IXa, IXb, IXc and IXd) and is related to the fact that the enzyme is a tetramer of four

protein subunts $(\alpha, \beta, \gamma$ and $\delta)$ each being encoded by a separate gene. The overall incidence of type IX is around 1 in $100,000{ }^{65}$ and is characterised by deficiency of the enzyme phosphorylase $\mathrm{b}$ kinase in muscle and or liver. The normal function of this enzyme being to convert the inactive form of phosphorylase (phosphorylase a) to it's active form (phosphorylase b).

The condition was first described in the $1960 \mathrm{~s}^{66}$ and involves mutations of the PHKA1, PHKA2, PHKB or PHKG2 genes and is subject to autosomal recessive or X-linked inheritance ${ }^{67}$. Since females have two $\mathrm{X}$ chromosomes but one is subject to ' $\mathrm{X}$ inactivation ${ }^{68}$, which is in itself random such that, some cells have one of the Xs activated whilst others have the other one inactivated, it is extremely difficult to predict expression or anticipate symptoms as a multitude of permutations is possible. Females with a disease gene on one $\mathrm{X}$ chromosome are carriers of the disease but only experience symptoms of the disease themselves if the mutated gene is the one which is active in a larger percentage of cells ${ }^{69}$. For both manifesting carriers and those inheriting the condition, there is considerable genetic variation which greatly increases the range of possible phenotypic expression. Accordingly, symptoms can range from mild to severe. 
Common symptoms of the liver form include hepatomegaly, hypoglycaemia during fasting and growth impairment ${ }^{70}$. The muscle form of the condition is much rarer and very infrequently reported, making characterisation extremely difficult.

\section{B-enolase deficiency/ GSD type XIII}

This is a very rare, and only very recently reported, disorder of the catalysis between 2-phosphoglycerate and phosphoenol pyruvate (intermediaries of the Embden-MeyerhofParnas pathway) and was first reported by Comi et al in $2001^{71}$. Only two papers have been published describing just three patients in total ${ }^{71},{ }^{72}$. Autosomal recessive mutations in ENO3 are responsible for the documented cases to date ${ }^{72}$, however, other gene mutations may be possible as beta-enolase comprises three subunits $(\alpha, \beta$, and $\Upsilon$ ) each encoded by different genes. The $\alpha$ subunit has been identified in many different tissues whilst $\beta$ is mostly found in muscle and $\Upsilon$ in nervous tissue ${ }^{73}$.

The condition is milder than McArdle disease and symptoms include exercise intolerance, myalgia, contracture, generalised muscle weakness after exercise, hyperCKaemia and myoglobinuria although onset of symptoms is hard to define as in one individual significant problems (substantial rhabdomyolysis) were not reported until middle age whilst another patient reported problems since childhood ${ }^{71}$. With the advent of next generation sequencing to aid diagnosis, it seems likely that milder disorders such as this will be shown to be more common than previously thought, our centre has just diagnosed a second patient within 18 months of the first described in Masumeci et al ${ }^{72}$. However, with so few patients identified to date, the clinical picture for ß-enolase deficiency has yet to be fully elucidated.

\section{PGM1 deficiency}

PGM1 deficiency has been described as a cause of exercise intolerance and rhabdomyolysis in adults ${ }^{74}$, but a novel presentation of this Glycogen storage disorder was identified by chance as part of an exome sequencing project to identify the causative mutation 
in a number of individuals thought to have a disorder of glycosylation ${ }^{75}$. PGM1 catalyzes the bidirectional transfer of phosphate from position 1 to 6 on glucose. Glucose-1-P and UDPglucose are closely linked to galactose metabolism, thus all of the patients had abnormal transferrin glycoforms. Clinical features included dysmorphic features including cleft palate and bifid uvula, short stature, and accessory thumbs. Other features included a raised CK, myopathy, rhabdomyolysis liver disease and cardiomyopathy ${ }^{74}$. Galactose supplementation, at least in vitro has been shown to correct the defect in glycosylation and thus offers a potential therapeutic strategy as yet to be tested in patients ${ }^{75,76}$.

\section{Other rare related glycolytic disorders}

The remaining disorders in the glycolytic pathway are extremely rare, all present in a similar way with exercise intolerance with/or without episodes of rhabdomyolysis. Phosphoglycerate mutase is caused by autosomal recessive mutations in PGAM2 and there

may be an associated finding of tubular aggregates in muscle biopsy ${ }^{77,78}$. The majority $(9 / 14)$ of affected individuals reported so far are of African American descent, symptoms are relatively mild compared with McArdle disease and are induced only by strenuous physical exertion $^{79,80}$.

Phosphoglycerate kinase deficiency has been reported in males presenting with haemolytic anaemia with or without neurological features including parkinsonism and/or learning difficulties and myopathy with exercise intolerance ${ }^{81,82,83}$. Inheritance is sex linked recessive. In one case the haemolytic anaemia was severe enough to warrant blood transfusion at a young age before the onset of myopathic symptoms ${ }^{84}$.

Lactate dehydrogenase A subunit deficiency was first reported in 1980 and is very rare with only nine families reported world-wide, six of whom are of Japanese origin. It presents with exercise intolerance and myoglobinuria and in some patients there are typical skin lesions ${ }^{85,86,87}$. 


\section{Summary and conclusions}

In summary, disorders of glyco(geno)lysis are associated with exercise induced symptoms occurring within a few minutes of aerobic activity, an inability to perform isometric muscle activities and a risk for muscle contracture and acute rhabdomyolysis with a risk of acute renal failure. The presence of additional features such as haemolytic anaemia, neurological, skin, hepatic and/or cardiomyopathy can point to specific enzyme deficiencies and aid diagnosis. There is no specific treatment for any of these disorders but aerobic training with exercise prescription is important for improving fat oxidation through conditioning and reducing the attendant health risks of a sedentary life style. Due to the rarity of these disorders there remain questions about natural history and long term consequences of a sedentary life-style. In 2015 a registry, funded by the European Union, was established (www.euromacregistry.eu) which, it is hoped, will provide useful data on the prevalence and natural history of these disorders as well as providing a platform for future clinical trials ${ }^{88}$.

\section{Acknowledgements:}

We wish to acknowledge the European Union for funding the EUROMAC network and NHS England for funding our nationally commissioned service. We wish to thank the AGSDUK for their continuing support and MDUK who are currently funding a trial of valproate in McArdle disease.

\section{References}

1. Ozen, H. Glycogen storage diseases: new perspectives. World J. Gastroenterol. 13(18):2541-53 (2007).

2. Naaman Boustany, R-M. Lysosomal storage diseases - the horizon expands. Nat. Revs. Neurol. 9: 583-598 (2013) 
3. Levine, J.A. Non-exercise activity thermogenesis. Proc. Nutr. Soc. 62:667-679 (2003).

4. Quinlivan R1, Buckley J, James M, Twist A, Ball S, Duno M, Vissing J, Bruno C, Cassandrini D, Roberts M, Winer J, Rose M, Sewry C. McArdle disease: a clinical review. J Neurol Neurosurg Psychiatry. 81(11):1182-8 (2010).

5. Preisler, N., Haller, R.G., Vissing, J. Exercise in muscle glycogen storage diseases. $J$. Inherit. Metab. Dis. 38: 551-563 (2015).

6. McArdle, B. Myopathy due to a defect in muscle glycogen breakdown. Clin. Sci. 10(1):13-35 (1951).

7. Tsujino, S., Shanske, S., DiMauro, S. Molecular genetic heterogeneity of myophosphorylase deficiency (McArdle disease). N. Engl. J. Med. 329:241245(1993).

8. Nogales-Gadea, G., Brull, A., Santalla, A., Andreu, A.L., Arenas, J., Martin, M.A., Lucia, A., de Luna, N., Pinos, T. McArdle Disease: Update of reported mutations and polymorphisms in the PYGM gene. Hum. Mutat. doi: 10.1002/humu.22806. [Epub ahead of print] (2015).

9. DeCastro, M., Johnston, J., Biesecker, L. Determining the prevalence of McArdle disease from gene frequency by analysis of next-generation sequencing data. Genet Med. Doi: 10.1038/gim.2015.9 (2015).

10. Lucia A1, Ruiz JR, Santalla A, Nogales-Gadea G, Rubio JC, García-Consuegra I, Cabello A, Pérez M, Teijeira S, Vieitez I, Navarro C, Arenas J, Martin MA, Andreu AL. Genotypic and phenotypic features of McArdle disease: insights from the Spanish national registry. J Neurol Neurosurg Psychiatry. 83(3):322-8 (2012). 
11. Vissing, J., Duno, M., Schwartz, M., Haller, R. G. Splice mutations preserve myophosphorylase activity that ameliorates the phenotype in McArdle disease. Brain 132:1545-1552 (2009)

12. McArdle, W.D., Katch, F.I., Katch, V.L. Essentials of Exercise Physiology. Second edition. Lippincott Williams \& Wilkins, Pennsylvania (2000).

13. Huxley, H., Hanson, J. Changes in the cross-striations of muscle during contraction and stretch and their structural interpretation. Nature 173(4412):973-6 (1954).

14. Huxley, A., Neidergerke, R. Structural changes in muscle during contraction; interference microscopy of living muscle fibres. Nature 173(4412):971-3 (1954).

15. Pearson, C,M., Rimer, D.G., Mommaerts, W.F. A metabolic myopathy due to absence of muscle myophorylase. Am. J. Med. 30:502-17(1961).

16. Vissing J., Haller R. A diagnostic cycle test for McArdle's Disease. Ann. Neurol. 54:539-542 (2003).

17. Gladden, L.B. Muscle as a consumer of lactate. Med Sci Sports Exerc. 32:764771.(2000)

18. Donovan, C.M., Pagliassotti MJ. Quantitative assessment of pathways for lactate disposal in skeletal muscle fiber types. Med Sci Sports Exerc. 32:772-777. (2000).

19. Gruener, R., McArdle, B., Ryman, B.E., Weller, R.O. Contracture of phosphorylase deficient muscle. J. Neurol. Neurosurg. Psychiat. 31:268-283(1968).

20. Vissing J1, Haller RG. A diagnostic cycle test for McArdle's disease. Ann Neurol. 54(4):539-42 (2003)

21. Buckley, J., Quinlivan, R.M., Sim, J., Eston, R.G., Short, D.S. Heart rate and perceived pain responses to a functional walking test in McArdle Disease. J. Sports. Sci. Doi: 10.1080/02640414.2014.906045 (2014). 
22. Borg, G.A.V. Borg's perceived exertion and pain scales. Champaign. IL: Human Kinetics (1998)

23. 'Start Active Stay Active', UK Dept. of Health guidelines, https://www.gov.uk/government/publications/start-active-stay-active-a-report-onphysical-activity-from-the-four-home-countries-chief-medical-officers (2011).

24. ACSM Position Stand: Quantity and quality of exercise for developing and maintaining cardiorespiratory, musculoskeletal and neuromotor fitness in apparently healthy adults: guidance for prescribing exercise. Med. Sci. Sports Exerc. 43(7): $1334-59(2011)$.

25. Blair, S.N., Koh,1 H.W., Paffenbarger, R.S., Clark, D.G., Cooper, K.H., Gibbons, L.W. Physical fitness and all-cause mortality. A prosective study of healthy men and women. JAMA 3;262(17):2395-401 (1989).

26. Kodama, S., Saito, K., Tanaka, S., Maki, M., Yachi, Y., Asumi, M., Sugawara, A., Totsuka, K., Shimano, H., Ohashi, Y., Tamada, N., Sone, H. Cardiorespiratory fitness as a quantitative predictor of all-cause mortality and cardiovascular events in healthy men and women: a meta-analysis. JAMA 20;301(19): 2024-35. Doi: 10.1001/jama.2009.681 (2009).

27. Kavanagh, T., Mertens, D.J., Hamm, L.F., Beyene, J., Kennedy, J., Corey, P, Shephard, R.J. Prediction of Long-Term Prognosis in 12169 Men Referred for Cardiac Rehabilitation. Circ. 106: 666-671 (2002).

28. Kavanagh, T., Mertens, D.J., Hamm, L.F., Beyene, J., Kennedy, J., Corey, P., Shephard, R.J. Peak oxygen intake and cardiac mortality in women referred for cardiac rehabilitation. J Am Coll Cardiol. 42(12): 2139-43 (2003). 
29. Myers, J., Prakash, M., Froelicher, V., Partington, S., Atwood, J.E. Exercise capacity and mortality among men referred for exercise testing. New Engl J Med. 346(11):793$801(2002)$.

30. García-Benítez S1, Fleck SJ, Naclerio F, Martín MA, Lucia A. Resistance (weight lifting) training in an adolescent with McArdle disease. J Child Neurol. 28(6):805-8 (2013).

31. Babraj, J.A., Vollaard, N.B.J., Keast, C., Guppy, F.M., Cottrell, G., Timmons, J.A. Extremely short duration high intensity interval training substantially improves insulin action in young males. BMC Endocrine Disorders 9:3 doi: 10.1186/14726823-9-3. (2009)

32. Hansen, D., Dendale, P., Jonkers, R.A., Beelen, M., Manders, R.J., Corluy, L., Mullens, A., Berger, J., Meeusen, R., van Loon, L.J. Continuous low- to moderateintensity exercise training is as effective as moderate- to high-intensity exercise at lowering blood $\mathrm{HbA}(1 \mathrm{c})$ in obese type 2 diabetes patients. Diabetologia 52(9): 178997. (2009)

33. Musa, D.I., Adeniran, S.A., Dikko, A.U., Sayers, S.P. The effect of a high-intensity interval traning program on high-density lipoprotein cholesterol in young men. $J$ Strength Cond Res 23(2): 587-592. (2009)

34. Tsekouras, Y.E., Magkos, F., Kellas, Y., Basioukas, K.N., Kavouras, S.A., Sidossis, L.S. High-intensity interval aerobic training reduces hepatic very low-density lipoprotein-triglyceride secretion rate in men. Am J Physiol Endocrinol Metab 295: E851-E858. (2008)

35. Burgomaster, K.A., Cermak, N.M., Phillips, S.M., Benton, C.R., Bonen, A., Gibala, M. Divergent response of metabolite transport proteins in human skeletal muscle after 
sprint interval training and detraining. Am. J. Physiol. Regul. Integr. Comp. Physiol. 292: R1970-R1976. (2007).

36. Talanian, J.L., Holloway, G.P., Snook, L.A., Heigenhauser, G.J., Bonen, A., Spriet, L.L. Exercise training increases sarcolemmal and mitochondrial fatty acid transport proteins in human skeletal muscle. Am. J. Physiol. Endocrinol. Metab. 299: E180E188 (2010).

37. Munguia-Izquierdo, D., Santalla, A., Lucia, A. Cardiorespiratory fitness, physical activtity and quality of life in patients with McArdle disease. Med Sci Sports Exerc. 47(4):799-808 (2015)

38. Haller, R.G., Wyrick, P., Taivassalo, T., Vissing, J. Aerobic conditioning: an effective therapy in McArdle's disease. Ann. Neurol. 59(6): 922-928 (2006).

39. Santalla, A., Munguia-Izquierdo, D., Brea-Alejo, L., Pagola-Aldazabal, I., DiezBermejo J., Fleck, S.J., Ara, I., Lucia, A. Feasibility of resistance training in adult McArdle patients: clinical outcomes and muscle strength and mass benefits. Frontiers Aging Neurosci. (2014) Doi:10.3389/fnagi.2014.0033.

40. Kley, R.A., Tarnopolsky, M.A., Vorgerd, M. Creatine for treating muscle disorders. Cochrane Database Syst. Rev. (2013). Doi: 10.1002/1465 1858.CD004760.pub4

41. Quinlivan, R., Martinuzzi, A., Schoser, B. Pharmacological and nutritional treatment for McArdle disease (Glycogen Storage Disease type V). Cochrane Database Syst. Rev. (2014). Doi: 10.1002/1465 1858.CD003458.pub5.

42. Vissing, J., Haller, R.G. The effect of oral sucrose on exercise tolerance in patients with McArdle's disease. New Engl. Med. 349(26):2503-2509 (2003).

43. Lucia, A., Nogales-Gadea, G., Perez, M., Martin, M.A., Andreu, A.L., Arenas, J. McArdle disease: what do neurologists need to know? Nat. Clin. Pract. Neurol. 4(10): $568-77,2008$ 
44. Andersen, S.T., Haller, R.G., Vissing, J. Effect of oral sucrose shortly before exercise on work capacity in McArdle disease. Arch. Neurol. 65(6):786-9 (2008).

45. Ørngreen, M.C., Jeppesen, T.D., Andersen, S.T. Taivassalo, T., Hauersley, S., Preisler, N., Haller, R.G., van Hall, G., Vissing, J. Fat metabolism during exercise in patients with McArdle disease. Neurol. 72(8): 718-24 (2009).

46. M Vorgerd, J Zange Treatment of glycogenosys type V (McArdle disease) with creatine and ketogenic diet with clinical scores and with 31P-MRS on working leg muscle. Acta Myol. 26(1): 61-63 (2007)

47. Nogales-Gadea, G., Pinos, T., Lucia, A., Camara, Y., Brul,1 A., de Luna, N., Martin, M.A., Garcia-Arumi, E., Marti, R., Andreu, A.L. Knock-in mice for R50X mutation in the PYGM gene present with McArdle disease. Brain 135(Pt 7):2048-57. Doi: 10.1093/brain/aws141 (2012).

48. Howell, J. McC., Walker, K.R., Creed, K.E., Dunton, E., Davies, L., Quinlivan, R., Karpati, G. Phosporylase re-expression, increase in the force of contraction and decreased fatigue following notexin-induced muscle damage and regeneration in the ovine model of McArdle disease. Neuromusc. Dis. 24: 167-177 (2014).

49. Howell, J. McC., Dunton, E., Creed, K.E., Quinlivan, R., Sewry, C. Investigating sodium valproate as a treatment for McArdle disease in sheep. Neuromusc. Dis. 25: 111-119 (2015).

50. Shen, J., Bao, Y., Liu, H.-M., Lee, P., Leonard, J. V., Chen, Y.-T. Mutations in exon 3 of the glycogen debranching enzyme gene are associated with glycogen storage disease type III that is differentially expressed in liver and muscle. J. Clin. Invest. 98: 352-357 (1996).

51. Endo, Y., Horinishi, A., Vorgerd, M., Aoyama, Y., Ebara, T., Murase, T., Odawara, M., Podskarbi, T., Shin, Y. S., Okubo, M. Molecular analysis of the AGL gene: 
heterogeneity of mutations in patients with glycogen storage disease type III from Germany, Canada, Afghanistan, Iran, and Turkey. J. Hum. Genet. 51: 958-963 (2006).

52. Van Hoof, F., Hers, H. G. The subgroups of type III glycogenosis. Europ. J. Biochem. 2: 265-270 (1967).

53. Ding, J.-H., de Barsy, T., Brown, B. I., Coleman, R. A., Chen, Y.-T. Immunoblot analyses of glycogen debranching enzyme in different subtypes of glycogen storage disease type III. J. Pediat. 116: 95-100 (1990).

54. Priya S Kishnani, Stephanie L Austin, Pamela Arn et al. Glycogen Storage Disease Type III diagnosis and management guidelines. Genetics in Medicine 12, 446-463 (2010).

55. Preisler, N., Pradel, A., Husu, E., Madsen, K.L., Becquemin, M-H., Mollet, A., Labrune, P., Petit, F., Hogrel, J-Y., Jardel, C., Maillot, F., Vissing, J., Laforet, P. Exercise intolerance in glycogen storage disease type III: weakness or energy deficiency. Mol. Gen. Metab. 109: 14-20 (2013).

56. Preisler, N., Laforet, P., Madsen, K.L., Prahm, K.P., Hedermann, G., Vissing, C.R., Galbo, H., Vissing, J. Skeletal muscle metabolism is impaired during exercise in glycogen storage disease type III. Neurol. 84(17): 1767-71 (2015).

57. Wary, C., Nadaj-Pakleza, A., Laforet, P., Claeys, K.G., Carlier, R., Monnet, A., Fleury, S., Baligand, C., Eymard, B., Labrune, P., Carleier, P.G. Investigating glycogenosis type III with multi-parametric functional NMR imaging and spectroscopy. Neuromusc. Dis. 20: 548-558 (2010).

58. Tarui, S., Okuno, G., Okura, Y., Tanaka, T., Suda, M., Nishikawa, M. Phosphofructose deficiency in skeletal muscle. A new type of glycogenosis. Biochem. Biophys. Res. Commun. 19: 517-523 (1965). 
59. Vora, S., Seaman, C., Durham, S., Pionelli, S. Isoenzymes of human phosphofrustokinase identification and subunit structural characterisation of a new system. Proc. Natl. Acad. Sci. USA. 77: 62-6 (1980).

60. Toscano, A., Musumeci, O. Tarui disease and distal glycogenosis: clinical and genetic update. Acta Myologica. 26:105-107 (2007).

61. Ronquist, G., Rudolphi, O., Engstrom, I., Waldenstrom, A. Familial phosphofructokinase deficiency is associated with a disturbed calcium homeostasis in erythrocytes. J. Int. Med. 240: 85-95 (2001).

62. DiMauro S, Garone C. Metabolic disorders of fetal life: Glycogenoses and mitochondrial defects of the respiratory chain. Seminars in fetal and neonatal medicine 16:181-189 (2011)

63. Sherman, J.B., Raben, N., Nicastri, C., Argov, Z., Nakajima, H., Adams, E.M., Eng, C.M, Cowan, T.M., Plotz, P.H. Common mutations in the phosphofructokinase-M gene Ashkenazi Jewish patients with glycogenesis VII and their population frequency. Am. J. Hum. Genet. 55(2): 305-13 (1994).

64. Smith, B.F., Stedman, H., Rajpurohit. Y., Henthorn, P.S., Wolfe, J.H., Patterson, D.F., Giger, U. Molecular basis of canine muscle type phosphofructokinase deficiency. $J$. Biol. Chem. 27(33): 20070-20074 (1996).

65. Maichele, A.J., Burwinkel, B., Maire, I., Sovik, O., Kilimann, M.W. Mutations in the testis/liver isoform of the phosphorylase kinase gamma subunit (PHKG2) cause autosomal liver glycogenosis in gsd rat and in humans. Nat. Genet. 14:337-340 (1996).

66. Hug, G., Schubert, W.K., Chuck, G. Phosphorylase kinase of the liver: deficiency in a girl with increased hepatic glycogen. Science. 153(3743): 1534-5 (1966). 
67. Beauchamp NJ, Dalton A, Ramaswami U, Niinikoski H, Mention K, Kenny P, Kolho KL, Raiman J, Walter J, Treacy E, Tanner S, Sharrard M. Glycogen storage disease type IX: High variability in clinical phenotype. Mol Genet Metab. 92:88-99 (2007)

68. Lyon, M.F. Gene action in the X-chromosome of the mouse (Mus musculus L.). Nature 190: 372-373 (1961).

69. Bali, D.S., Goldstein, J.L., Fredrickson, K., Rehder, C., Boney, A., Austin, S., Weinstein, D.A., Lutz, R., Boneh, A., Kishnani, P.S. Variability of disease spectrum in children with liver phosphrylase kinase deficiency caused by mutations in the PHKG2 gene. Mol. Genet. Metab. 111(3): 309-13 (2014).

70. Kishnani, P., Koeberl, D., Chen, Y.T. Glycogen Storage Diseases Scrivener's Online Metabolic and Molecular Bases of inherited Disease. Valle; Beaudet; Vogelstein; Kinzler; Antonarakis; Ballabio, editors (2009).

71. Comi, G.P., Fortunato, F., Lucchiari, S., Bordoni, A., Prelle, A., Jann, S., Keller, A., Ciscato, P., Galbiati, S., Chiveri, L., Torrente, T., Scarlato, G., Bresolin, N. Betaenolase deficiency, a new metabolic myopathy of distal glycolysis. Ann. Neurol. 50: 202-207, 2001.

72. Musumeci, O., Brady, S., Rodolico, C., Ciranni, A., Montagnese, F., Aguennouz, M., Kirk, R., Allen, E., Godfrey, R., Romeo, S., Murphy, E., Rahman, S., Quinlivan, R., Toscano, A. Recurrent rhabdomyolysis due to muscle $\beta$-enolase deficiency: very rare or underestimated. J. Neurol. 261: 2424-2428, 2014.

73. Chen, S-H., Giblett, E.R. Enolase: human tissue distribution and evidence for three different loci. Ann Hum Genet. 39: 277-280, 1976.

74. Stojkovic T, Vissing J, Petit F et al. Muscle glycogenosis due to phosphoglucomutase 1 deficiency. N Engl J Med 361; 425-7 (2009) 
75. L.C. Tegtmeyer, S. Rust, M. van Scherpenzeel, B.G. Ng, M.-E. Losfeld Multiple Phenotypes in Phosphoglucomutase 1 Deficiency. N Engl J Med 370:533-42 (2014)

76. Galactose supplementation in phosphoglucomutase-1 deficiency; review and outlook for a novel treatable CDG. [Review] Morava E. Molecular Genetics \& Metabolism. 112(4):275-9 (2014)

77. Salameh J; Goyal N; Choudry R; Camelo-Piragua S; Chong PS. Phosphoglycerate mutase deficiency with tubular aggregates in a patient from Panama. Muscle \& Nerve. 47(1):138-40 (2013)

78. Oh SJ; Park KS; Ryan HF Jr; Danon MJ; Lu J; Naini AB; DiMauro S.Exerciseinduced cramp, myoglobinuria, and tubular aggregates in phosphoglycerate mutase deficiency. Muscle \& Nerve. 34(5):572-6, 2006 Nov.)

79. Tsujino S; Shanske S; Sakoda S; Toscano A; DiMauro S. Molecular genetic studies in muscle phosphoglycerate mutase (PGAM-M) deficiency. Muscle \& Nerve Supplement. 3:S50-3 (1995)

80. Tonin P; Bruno C; Cassandrini D; Savio C; Tavazzi E; Tomelleri G; Piccolo G Unusual presentation of phosphoglycerate mutase deficiency due to two different mutations in PGAM-M gene. Neuromuscular Disorders. 19(11):776-8 (2009)

81. Fujii H; Miwa S. Other erythrocyte enzyme deficiencies associated with nonhaematological symptoms: phosphoglycerate kinase and phosphofructokinase deficiency. [Review] [49 refs] Bailliere's Best Practice in Clinical Haematology. 13(1):141-8 (2000).

82. Spiegel R; Gomez EA; Akman HO; Krishna S; Horovitz Y; DiMauro S. Myopathic form of phosphoglycerate kinase (PGK) deficiency: a new case and pathogenic considerations. Neuromuscular Disorders. 19(3):207-11 (2009) 
83. Sotiriou E; Greene P; Krishna S; Hirano M; DiMauro S. Myopathy and parkinsonism in phosphoglycerate kinase deficiency. Muscle \& Nerve. 41(5):707-10, 2010 May.

84. Tamai M; Kawano T; Saito R; Sakurai K; Saito Y; Yamada H; Ida H; Akiyama M. Phosphoglycerate kinase deficiency due to a novel mutation (c. 1180A>G) manifesting as chronic hemolytic anemia in a Japanese boy. International Journal of Hematology. 100(4):393-7 (2014).

85. Miyajima H; Takahashi Y; Kaneko E. Characterization of the oxidative metabolism in lactate dehydrogenase A deficiency. Internal Medicine. 34(6):502-6 (1995)

86. Kanno T; Maekawa M. Lactate dehydrogenase M-subunit deficiencies: clinical features, metabolic background, and genetic heterogeneities. Muscle \& Nerve Supplement. 3:S54-60 (1995).

87. Hidaka K; Ueda N; Hirata I; Watanabe Y; Minatogawa Y; Iuchi I. First case of missense mutation (LDH-H:R171P) in exon 4 of the lactate dehydrogenase gene detected in a Japanese patient. Journal of Human Genetics. 44(1):69-72 (1999).

88. Quinlivan R, Lucia A, Scalco R, Santalla A, Pattni J, Godfrey R, Marti R on behalf of the workshop participants. Report on the EUROMAC McArdle testing exercise workshop. Madrid Spain 11-12 July 2014. Neuromuscular Disorders 2015 In Press 
Figure 1

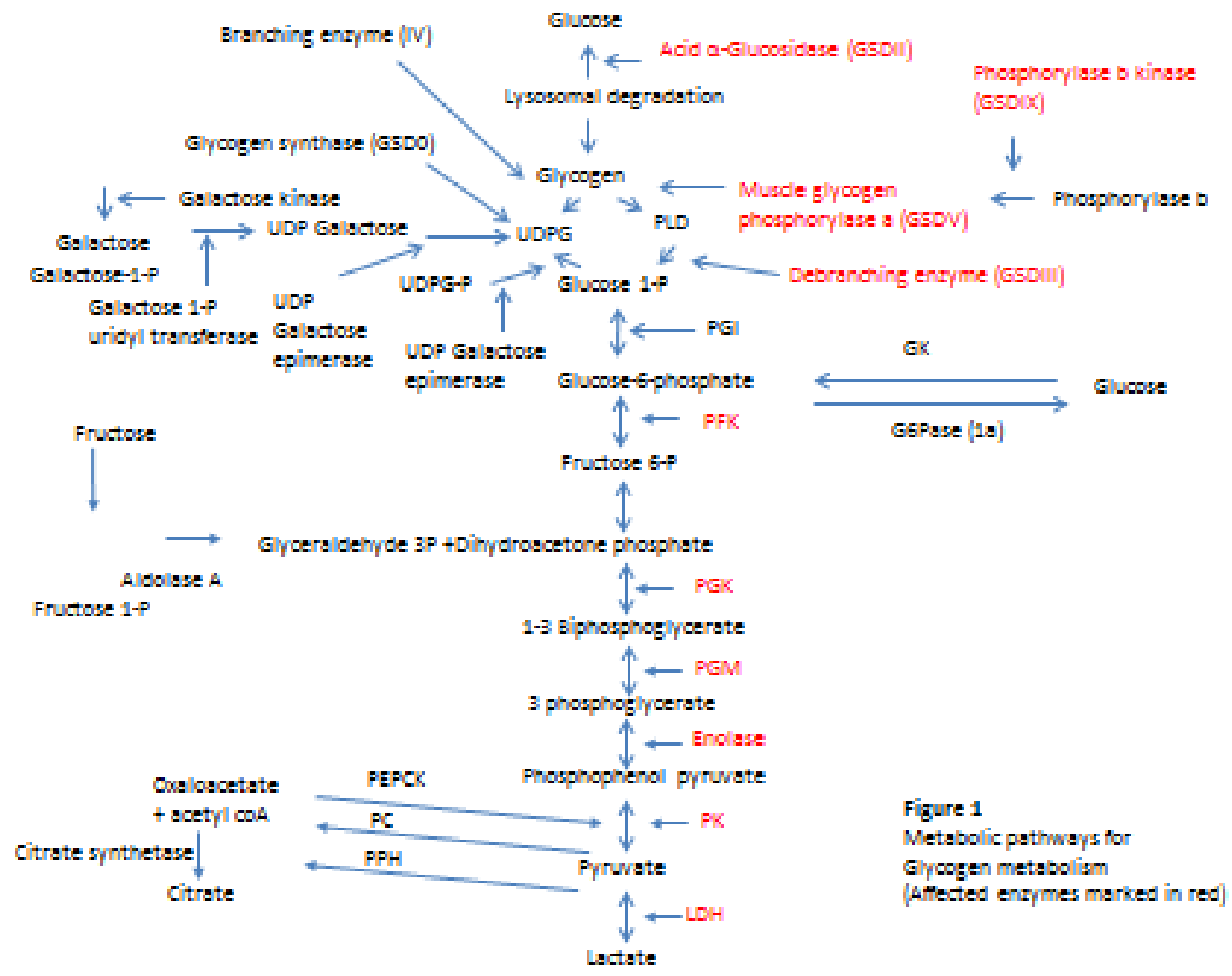

Figure 2

In individuals without pathology carbohydrate is distributed as $400 \mathrm{~g}$ of glycogen in muscle, $100 \mathrm{~g}$ of glycogen in liver and $3 \mathrm{~g}$ of glucose in the systemic circulation. In McArdle patients > $400 \mathrm{~g}$ is stored in muscle, but is unavailable as a fuel substrate with only liver glycogen and blood glucose being available for metabolism. 


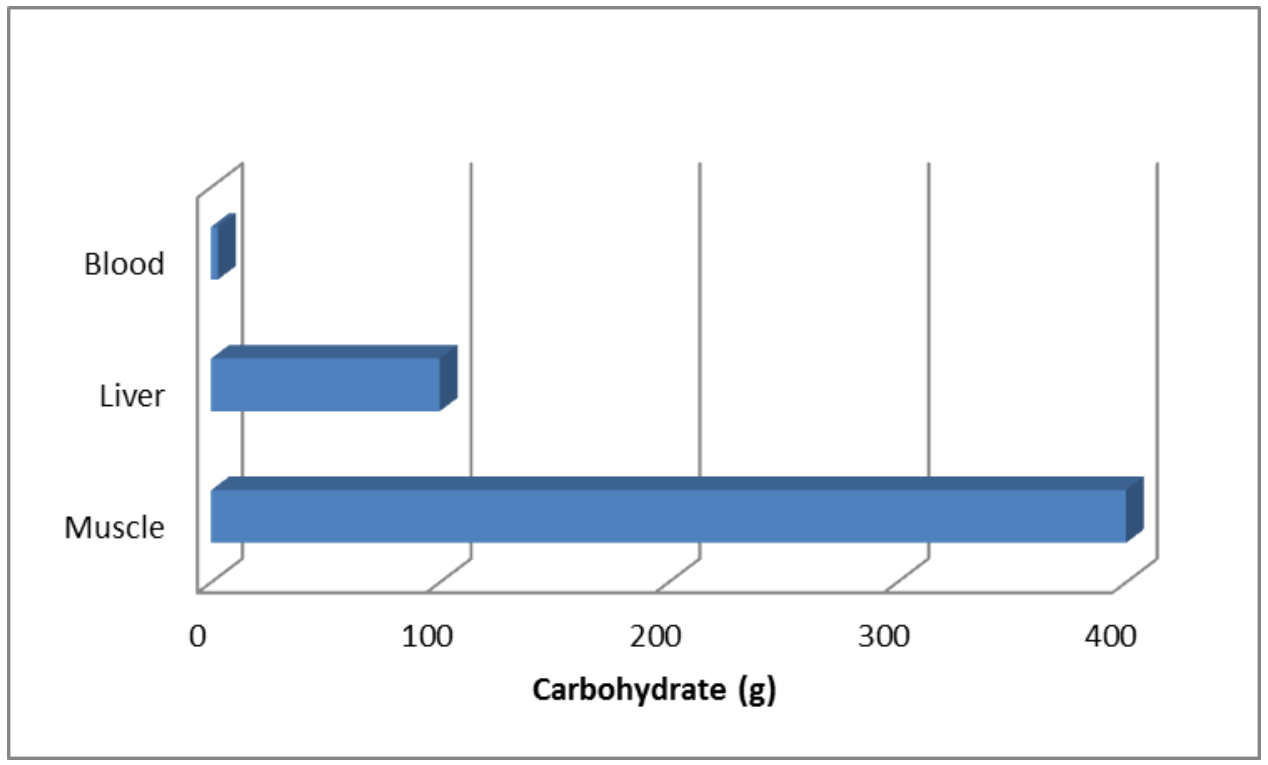

\section{Figure 3}
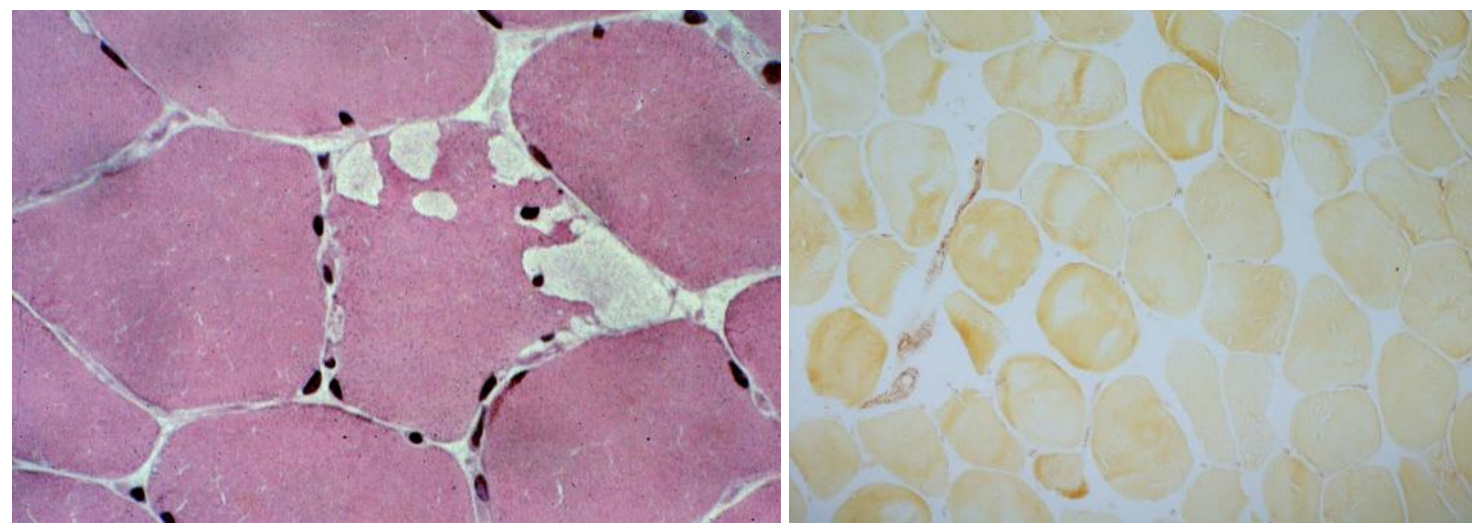

Muscle biopsy from a patient with McArdle disease, a) H\&E illustrating sub-sarcolemmal vacuoles with excess glycogen storage b) absent staining of muscle glycogen phosphorylase which is seen only in the smooth muscle of blood vessels (foetal/brain isoform).

\section{Figure 4}

\section{Blood lactate concentration with exercise}




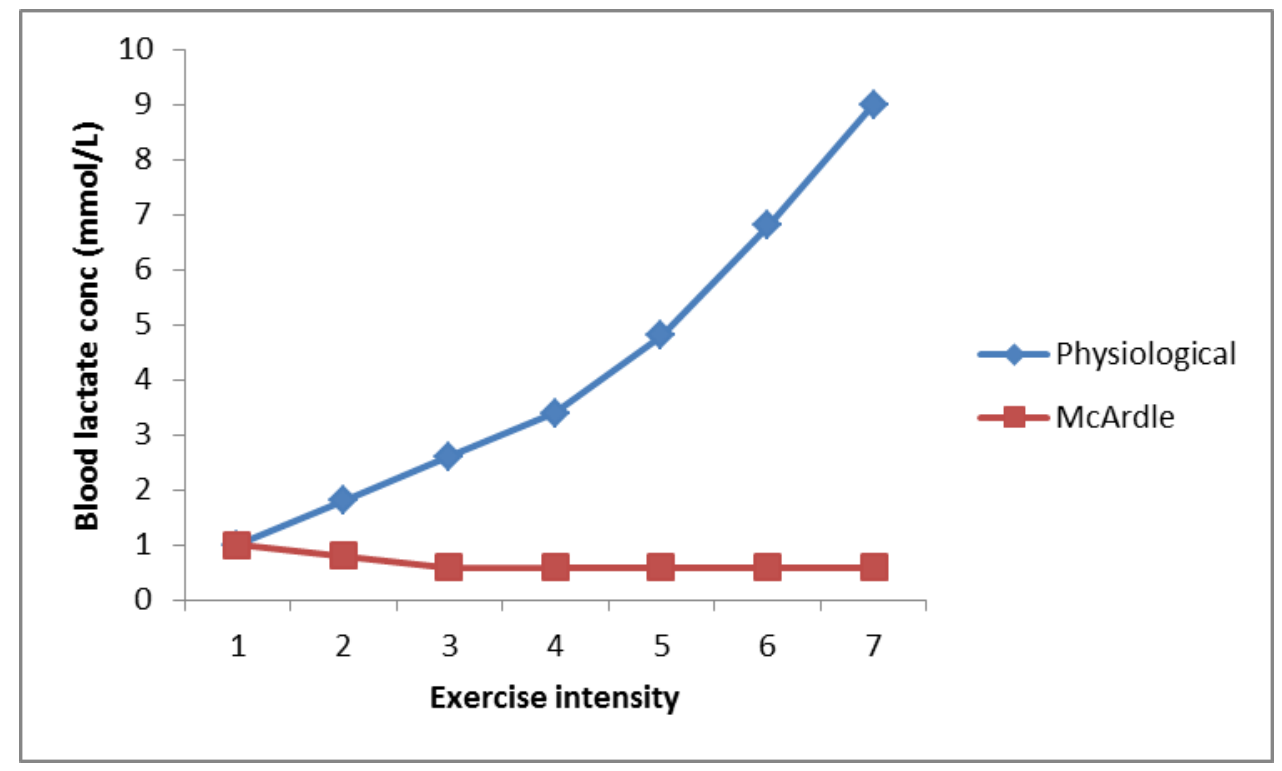

With increasing exercise intensity healthy individuals without pathology demonstrate a rise in

blood lactate concentration. In contrast, people with McArdle disease have a normal resting blood lactate concentration but this decreases at the start of exercise and remains low throughout despite increasing exercise intensity.

\section{Table 1}

Skeletal muscle disorders of Glyco(geno)lysis covered by this review

\begin{tabular}{|c|c|c|c|}
\hline Enzyme & Gene & Inheritance & Features \\
\hline $\begin{array}{l}\text { Phosphorylase } \\
\text { deficiency }\end{array}$ & PYGM & $A R$ & $\begin{array}{l}\text { Exercise intolerance, myoglobinuria, second } \\
\text { wind, } \\
\text { Skeletal muscle atrophy } \\
\text { and weakness, gout }\end{array}$ \\
\hline $\begin{array}{l}\text { Amylo- } 1,6-\alpha- \\
\text { glucosidase, } 4-\alpha- \\
\text { glucotransferase }\end{array}$ & AGL & $A R$ & $\begin{array}{l}\text { Type IIla skeletal and cardiac muscle atrophy } \\
\text { and weakness, } \\
\text { IIIc skeletal/cardiac muscle and } \\
\text { liver, types IIIb and IIId liver only }\end{array}$ \\
\hline $\begin{array}{l}\text { Phosphofructokinase } \\
\text { deficiency }\end{array}$ & PFKM & AR & $\begin{array}{l}\text { Vomiting with exercise, exercise intolerance, } \\
\text { Myoglobinuria, muscle atrophy and } \\
\text { weakness, gout, } \\
\text { haemolytic anaemia. Neonatal form with } \\
\text { arthrogryposis }\end{array}$ \\
\hline Phosphorylase B kinase & PHKG1 & AR & $?$ \\
\hline
\end{tabular}




\begin{tabular}{|c|c|c|c|}
\hline & PHKA1 & $A R$ & $\begin{array}{l}\text { Exercise intolerance } \\
\text { myoglobinuria }\end{array}$ \\
\hline & PHKA2 & $X L$ & $\begin{array}{l}\text { Liver disease exercise intolerance and } \\
\text { myoglobinuria }\end{array}$ \\
\hline & PHKB & $X L$ & $\begin{array}{l}\text { Liver disease, exercise intolerance and } \\
\text { myoglobinuria }\end{array}$ \\
\hline & PRKAG2 & AR & $\begin{array}{l}\text { WPW syndrome, } \\
\text { Hypertrophic cardiomyopathy }\end{array}$ \\
\hline Phosphoglucomutase 1 & PGM1 & AR & $\begin{array}{l}\text { Dysmorphic syndrome (short stature, } \\
\text { cleft palate, bifid uvula), exercise intolerance } \\
\text { and myoglobinuria } \\
\text { dilated cardiomyopathy, liver disease } \\
\text { abnormal transferrin } \\
\text { glycoforms }\end{array}$ \\
\hline $\begin{array}{l}\text { Phosphoglycerate } \\
\text { mutase }\end{array}$ & PGAM2 & $A R$ & $\begin{array}{l}\text { Exercise intolerance } \\
\text { myoglobinuria } \\
\text { Tubular aggregates in muscle biopsy }\end{array}$ \\
\hline $\begin{array}{l}\text { Phosphoglycerate } \\
\text { kinase }\end{array}$ & PGK & $X L$ & $\begin{array}{l}\text { Exercise intolerance } \\
\text { myoglobinuria } \\
\text { Haemolytic anaemia, } \\
\text { Learning difficulty, parkinsonism }\end{array}$ \\
\hline Lactate dehydrogenase & LDHA & AR & $\begin{array}{l}\text { Exercise intolerance, } \\
\text { myoglobinuria, } \\
\text { Skin rash }\end{array}$ \\
\hline
\end{tabular}

